\title{
MEMORY OF WATER - WATER AS A MEDIUM OF INFORMATION TRANSFER
}

\author{
Saša Zavrtnik*, Jelena Loborec ${ }^{*}$, Damir Žubčić*** , Goran Sabol ${ }^{* * * *}$ \\ * University of Zagreb, Faculty of Geotechnical Engineering, Varaždin, Croatia \\ ${ }^{* *}$ University of Zagreb, Faculty of Veterinary Medicine, Zagreb, Croatia \\ ${ }^{* * *}$ Polytechnic of Međimurje in Čakovec, Čakovec, Croatia \\ corresponding author: Saša Zavrtnik, e-mail: zavrtnik@gfv.hr
}

\begin{abstract}
Water is one of the five elements that man has been in connection with in a continuous, special and profound way throughout history. By its structure, an angle between atoms, polarity, binding, no doubt it is a fascinating element. Water comes in three aggregate states; it is a universal solvent and, interestingly, a rare substance on Earth whose density is decreased if water temperature is below 4 ${ }^{\circ} \mathrm{C}$. This is why ice floats on water surface and what makes life possible. Recent very interesting studies have been made that point out the ability of water to store and transfer information. Aquaphotomics studies a so-far unknown world of water in a scientific way. There seems to be an influence on water and its structure through words, music, DNA, etc., via electromagnetic signals. The last four decades gave us an interesting insight through some interesting experiments. This should guide us not just to see the water in its chemical composition, but to see its spatial order of molecules too. Having this knowledge we should examine ourselves, fundamentally, based on the information we share and transmit. All human communication, negative or positive, and human action with and towards water can be reflected in the functioning of the human organism, other living beings, and the ecosystems that they are part of and interfere in.
\end{abstract}

Keywords: water, structure, memory, information

\section{INTRODUCTION}

Water is one of the five elements connected to man in an uninterrupted, special, and profound way throughout history. Indeed, that relationship used to be more profound than it is today. For humans, water has always been, and still is, a matter of existence. Nomads moved towards the water, and settlements, city-states were established close to water. In other words, humans built their settlements where there was water for cattle and crop irrigation. Thus, fertile lowlands along rivers were the cradle of civilization; for example, along the Euphrates and the Tigris in Mesopotamia or along the Nile in Ancient Egypt. But people did not use water for drinking and preparing food only; they used it 
to maintain physical and spiritual health, too. Water was present in various rituals and solemn ceremonies of purification and was seen as an element, a medium, with special properties and powers. It was considered sacred.

Today, water, together with all its problems, is very relevant as a geostrategic resource that is endangered by the negligent, irresponsible, and selfish behaviour of the humans. Unfortunately, it is not yet fully known to us, but some water systems have been irretrievably destroyed. So far, the focus in dealing with water has been on the chemical properties of water, while the physical, thermodynamic and quantum properties are yet to be discovered. For this reason, it would be wise to properly and responsibly approach this dominant and ubiquitous element so as not to harm the way and the areas of water properties and behaviour that will be revealed in the future and have yet to be learned.

This papers aim is to give an insight into this interesting and not very well explored subject of the ability of water to store and transmit received information in a certain way. Chemical compounds of water are very well explored on daily basis, but some researchers have turned to see its physical characteristics, like the spatial order of molecules and their behaviour when exposed to certain electromagnetic signals. This all started some 40 years ago and still is an ongoing pursuit.

\section{KNOWLEDGE OF THE STRUCTURE OF WATER AND ITS ROLE}

Water, as one of the basic elements of life, has always been of great importance among people. It is not surprising that it was viewed with a dose of mysticism, as something inexplicably purifying, even sacred. Water is probably the most abundant substance on Earth. With its three states of matter, in the form of water vapour, liquid and solid as snow and ice, it is present in the atmosphere, hydrosphere and lithosphere at all ends of this planet. By its circulating in nature, the hydrologic cycle, water is accessible to all living beings. By its structure, polarity, binding, and the role as the universal solvent water comes into contact with countless elements and compounds in the biosphere dissolving and carrying them away.

Ice, which is a solid state of water where molecules are interconnected by hydrogen bonds, is one feature on which life on Earth largely depends. As the temperature drops below $-4{ }^{\circ} \mathrm{C}$, more precisely $-3.8{ }^{\circ} \mathrm{C}$ downwards, the density of water begins to decrease. The so-called water anomalies occur, and ice, being less dense than water, floats on its surface. This property helps to keep living organisms in the water from freezing in winter. The surface ice protects the rest of the water system from sudden changes in temperature, circulations that could harm it. If the ice became thicker than water as the temperature dropped below zero, it would sink to the bottom and all the living world that lives there would freeze. In addition to this property of water, there is the inevitable aesthetic dimension of uniqueness, speciality and beauty of snowflakes explained by the fractal structure and formation in conditions of a certain temperature, humidity, air flow, limited space for growth, which are not equal at every single point. Their role is reflected in the fact that they form a soft and airy snow cover that protects the soil as an organism, just like other living beings on and in it, from extreme frosts and cold air currents.

Water is considered to be the source of life. It is believed that life evolved in water and came out of it ashore. Life as such is inconceivable without water; there is no life where there is no water. It is common knowledge that water in the structure of our bodies as well as, interestingly, on the surface of our planet has a majority share of over $70 \%$. However, of the total water on Earth, only $2.5 \%$ is fresh water, of which only $0.3 \%$ is available for human consumption. This indicates how important our relationship is to the fresh water available to us, which, compared to abundance in terms of total quantity is relatively little in quantity. 
However, this has been neglected for a long time. So, it is not surprising that the water crisis has taken hold. This is exactly what the UN Water Organization emphasizes in one of its numerous publications when it claims that more people in the world die from the lack of drinking water than from violence, including wars [1].

\section{RELATION TO WATER}

Everyday life of the humans testifies that although we are well aware of the many dangers of our careless and irresponsible handling of water, it is still not uncommon for wastewater to be discharged into watercourses and the sea without treatment. In this way, man not only directly reduces the amount of water of appropriate quality for his needs, but by such behaviour endangers and changes many ecosystems and affects the continuous reduction of biodiversity. Only now is the true measure of pollution accumulated through decades of human activity coming to the fore, such as the creation of a "new island" of garbage in the Pacific Ocean that we leave to future generations as our legacy. In addition, there are incidents in local communities where the water in water supply systems becomes faulty due to accidental or intentional failures. Users often remain uninformed on this. New types of pollutants are emerging that have so far not been monitored at all in water for human consumption. It appears as if no one is thinking about the well-known proverb, "We are all downstream from someone" and waiting for the "water to take away" all the bad from us. If everything spreads globally, and the consequences of pollution of other components of the environment, soil and air, are also seen in the spirit of the relationship to water, climate change that causes water scarcity or catastrophic scenarios of destructive power of water shall pose a great threat to human survival.

In contrast to this, there is knowledge about 4000 years old where, for example, the scripture of Vinaya Pitaka has given the
Buddhist monks a detailed description of the daily religious rules of using drinking water and, separately, water for hygiene, digging wells, and more. The monks were strictly forbidden to throw waste into rivers or lakes, and contamination of water sources was considered to have serious karmic consequences [2]. Today, this is understandable in a cause-and-effect relationship given that we live on this planet in a somewhat closed system in which everything returns in some way. Nothing disappears, nor does it arise from anything, but matter circulates, passing from one form to another.

\section{WATER STRUCTURE AND ITS IMPORTANCE}

Ever since 1988, when the French biologist Jacques Benveniste published the results of his team's research in the journal Nature and in some way founded the term "water memory" [3], there has been no single response of the scientific community towards this phenomenon. Indeed, even after 30 years, various questions, doubts and interpretations arise on this topic, and it cannot be ignored [4, 5]. What still emerges today as relatively new, unknown, or rather insufficient is the ability of water to store and transmit information. The possibility of interpreting that the structure of water is more important than its chemical composition opens up. It is about the way in which water molecules are arranged and connected into "aggregates", so-called clusters. According to this interpretation, the molecular structure of water would be the alphabet of water. By deciphering that structure and the way in which it is achieved, that is, how some information is stored on it and passed on, it could affect that transfer and its content [6].

Aquaphotomics as a new discipline that studies the interrelationship of biological and aquatic systems, based on their interaction at the energy level, suggesting that water functions as a molecular mirror. Such an approach came about when it was proven that 
much can be learned about the organization of water molecules based on the spectrum of water in the near infrared spectrum (near infrared spectroscopy - NIR). This resulted in the application of a simple test for mastitis in cows (aquagram of milk), for infectious diseases in animal and human blood tests, for the detection of tumour cells in a sample of fresh tissue, for examination of plant health, then in the production, storage, and quality of food, in homeopathy [7]. Such diagnostics are faster, cheaper, more accurate, and more accessible.

The experiments conducted by the Japanese researcher Masaru Emoto are interesting and indicative. He exposed water to certain words for a while, whether spoken or written, with positive and negative meanings, music, photographs and even prayer. He would then freeze the water samples at $-20{ }^{\circ} \mathrm{C}$ for 3 hours. Certain crystals were obtained which were photographed under special conditions (Figure 1). It is astonishing that water samples exposed to words, music, prayers of positive meaning resulted in crystals of regular structure while those exposed to messages of negative content gave irregular crystals or amorphous ice [8].

From the above results of the research of water and its crystals, Emoto draws the conclusion that the way we treat children, for example, is important. They are developing and are mostly built of water. Indeed, we can extend his thought to an unborn child who, in addition to being largely built of water, grows and develops in amniotic fluid (Figure 2). That is why it is very important how mothers treat babies in their womb, how they communicate with them and that in that part of development unborn children "listen" because information can be "imprinted" in them in a certain way.

According to Emoto, the combination of words that gave the most striking crystals is love and gratitude [8]. Based on the above, the question is to what words do we expose the water we drink, we use to cook, bathe, sprinkle our fruits and vegetables, give to our animals? With what thoughts, intentions, words, do we expose the other person's water in itself as well as the one that person uses?

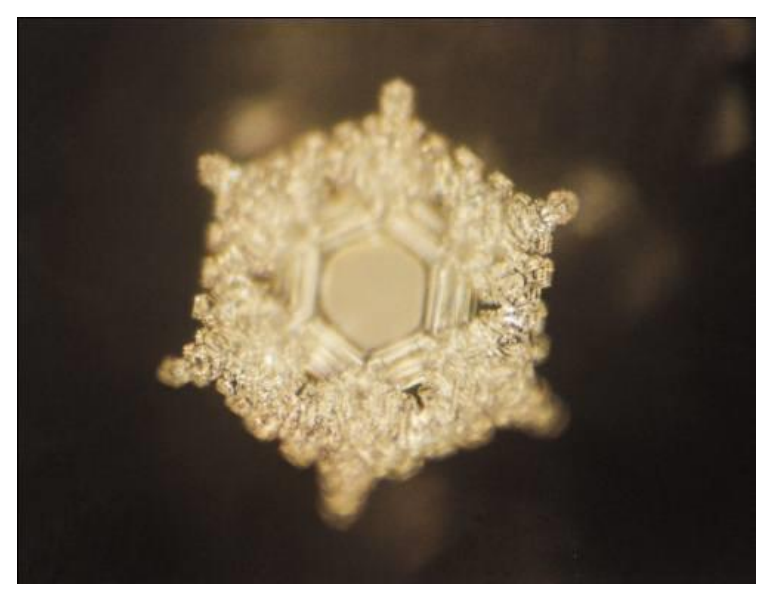

a)

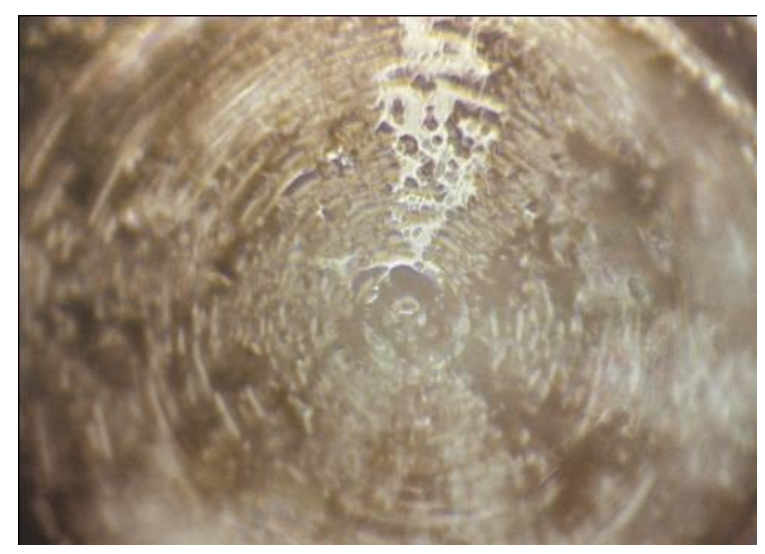

b)

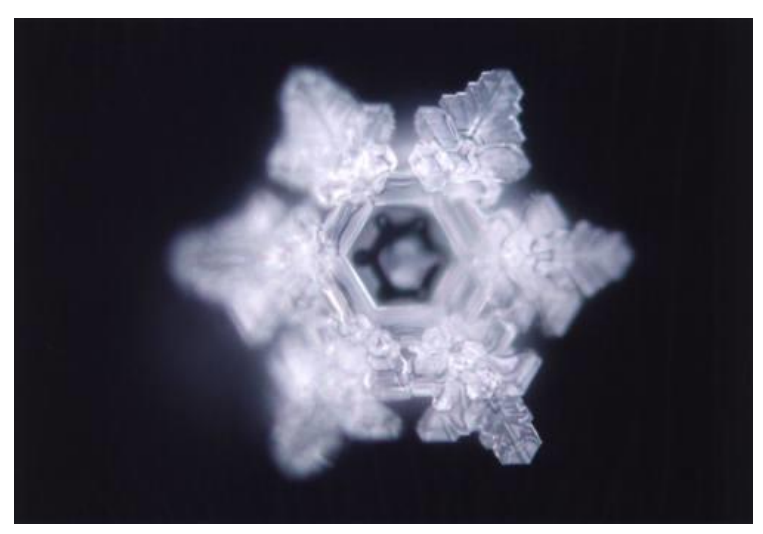

c)

Figure 1. Photographs of water crystals: a) exposed to the words "love and gratitude", b) heavy metal music, c) natural pristine water from Rocky Creek, Australia [9] 


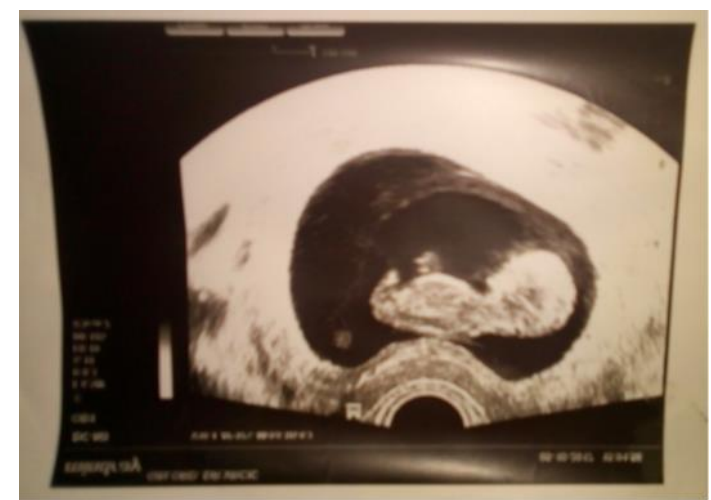

Figure 2. Ultrasound finding of a three-monthold child - a presentation of the child's development in amniotic fluid [10]

Deception is also a delusion that just because something cannot be seen it does not exist. Maybe looking from the beach the sea sometimes seems crystal clear, but somewhere "far far away" there is still a large accumulation of garbage in the Pacific Ocean (Figure 3) [11, 12]. Garbage from, for example, Albania and other southern countries is also flooded to the Croatian Adriatic coast. However, there are places on the planet where water is virginally intact. The water samples taken in Venezuela, on Mount Roraima showed 40,000 times higher energy activity than, for example, tap water [13] (although there is a marked difference between them).

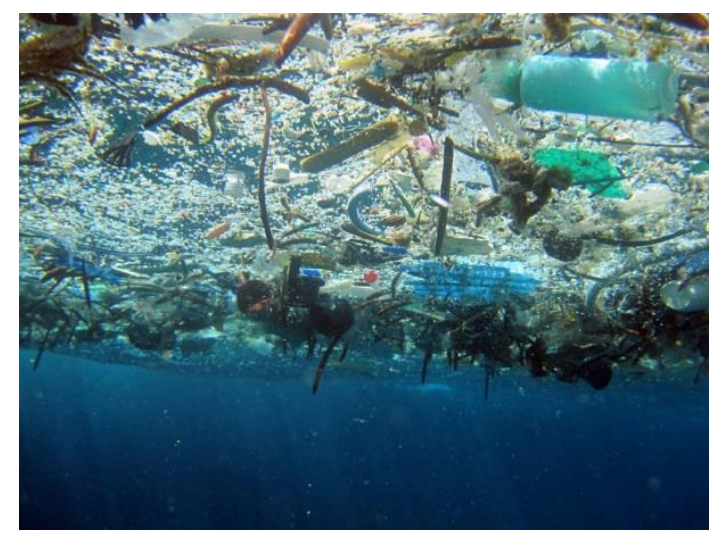

Figure 3. Large accumulation of floating debris in the Pacific Ocean - direct and longterm impact on the aquatic ecosystem [11]

Water is the right of every human being. According to the United Nations Declaration, every human being has the right to access the necessary amount of clean water as a precondition for other human rights and a dignified life [14]. Therefore, one should not selfishly destroy one's neighbour's water or expose it to information that could be passed on and harm someone, not to mention what we leave behind for future generations.

\section{ABILITY TO STORE AND TRANSMIT INFORMATION}

Research indicates that ordered thermodynamic regions of phases in space can be arranged to store information [15]. The same can obviously be said for water. Experimental work has shown that molecular activity in more than 50 biochemical systems, as well as in bacteria, could be induced by electromagnetic signals transmitted through aqueous solutions. Widom et al. write that the results suggest that the way the electromagnetic transmission of biochemical information can be stored in the electric dipole moment of water is similar to how magnetic moments store information on a computer disk. It also says that arranging water through coherent domains results in a sufficient structure for significant memory capacity. Both statistical thermodynamics and information theory support this view [15].

Similarly, Dunning-Davies has reported on another experiment where the essence of the result is that the aqueous antibody solution retains its stability to elicit a biological response even when diluted to the extent that the probability of a single molecule in the sample is negligible. It follows that arranging water with coherent domains results in a sufficient structure for truly significant memory capacity. He states that water is ferroelectric and that this is what is basically responsible for many of the intriguing properties of water, including its memory [16].

Montagnier, on the other hand, states that their published experiments indicate that the ability to generate an electromagnetic signal can be transferred from Sample 1, which contains a solution of the emitter's DNA, to Sample 2 of "natural" water. The prerequisite is that the 
system is excited through the night by electromagnetic waves of a minimum frequency of $7 \mathrm{~Hz}$. Judging by this, Sample 1 transmits waves to water in Sample 2, which in the original did not contain any traces of DNA from the source site of these signals [17]. This and similar research attempts to clarify how aqueous structures can store molecular information and transmit it by electromagnetic waves. Furthermore, it has been observed that amplification of the emitting DNA segment can be achieved using pure water exposed to the appropriate DNA electromagnetic signal and with the addition of enzymes, primers, etc. being subjected to PCR cycles. Under natural conditions, electromagnetic signals and nano-structures of water can play the role of imperceptible elements by transmitting DNA information of an infectious agent without being detected by the immune system or being invisible by conventional therapies [17]. This clearly confirms the ability of water to receive certain information and to transmit it further.

\section{CONCLUSION}

Nikola Tesla also uttered very wise words that have been talked about a lot lately: "If you want to find the secrets of the universe, think about energy, frequency and vibration". It is very likely the same for the secrets of water. There is a proven influence on water and its structure through words, music, DNA, etc., via electromagnetic signals. Water can store and transmit received information in a certain way. The human body is largely made up of water and every word is a medium with information. Consequently, we are part of the chain of information transmission, while each person is unique and an individual source of information. In this way, what is imprinted in the organism, in the water, can to a certain extent reflect on other living beings and perhaps on nature as a whole.

Based on the considered experiments and knowledge, we should certainly thoroughly reexamine what information we send and share with each other, since water is necessary for life and is an integral part of every living being. Therefore, all our communication, whether negative or positive, as well as each of our actions with and towards water, is reflected in the functioning of our organism, in other life forms and in the ecosystems of which we are a part and in which we irreversibly encroach. Given such properties of water, any small change for the better or for the worse can have significant consequences.

One thing is for sure: We may or may not agree with the claims and interpretations made here. We can believe that water has a memory or simply declare it to be misinterpreted, poorly performed experiments, or just ignore it. Yet the realization that water means life remains even vague in the spirit of this knowledge. It leaves room for upgrades. Sometimes the best solution would be to turn to the knowledge of ancient peoples and learn from their wisdom, their traditions that understood the true nature of reality and the impact of man on the world around him. Their intuitive knowledge often surpasses ours, and this is clearly visible from today's state of the world to which "progress" has brought us.

\section{REFERENCES}

[1] UN WATER - 10 Facts About the Water Crisis, https://lifewater.org/blog/worldwater-day-2018/, Accessed: June 21, 2018.

[2] D. Žubčić, Svijest o živome i savjestan život, Lecture within the forums of the Faculty of Geotechnical Engineering, University of Zagreb ,5 do 12 za okoliš“, Varaždin, Croatia, January 24, 2018.

[3] E. Davenas, F. Beauvais, J. Amara, M. Oberbaum, B. Robinzon, A. Miadonnai, A. Tedeschi, B. Pomeranz, P. Fortner, P. Belon, J. Sainte-Laudy, B. Poitevin, J. Benveniste, Human basophil degranulation triggered by very dilute antiserum against IgE, Nature 333(1988) 6176, 816-818. 
[4] G. Vithoulkas, The Controversy Over the "Memory of Water", Medical Science Hypotheses 4(2017), 1-6.

[5] F. Beauvais, Benveniste's Experiments Explained by a Non-Conventional Experimenter Effect, Medicines 5(2018) 2, Paper No. 28.

[6] S. Zavrtnik, J. Loborec, D. Žubčić, Memorija vode - voda kao medij prijenosa informacija, Abstracts book of $17^{\text {th }}$ Lošinj days of bioethics, ed. H. Jurić, Croatian Philosophical Society, Mali Lošinj, Croatia, May 20-23, 2018, 127-128.

[7] R. Tsenkova, Exploring Water Molecular System in Nature, http://www.aquaphotomics.com/,

Accessed: May 18, 2018.

[8] M. Emoto, Poruke skrivene u vodi, V.B.Z. d.o.o., Zagreb, 2005.

[9] Office Masaru Emoto LLC, http://www.masaruemoto.net/english/water-crystal.html, Accessed: May 18, 2018.

[10] S. Zavrtnik, author's photograph of the ultrasound finding, 2017.

[11] National Geographic, Great Pacific Garbage Patch, https://www.nationalgeographic.org/enc yclopedia/great-pacific-garbage-patch/, Accessed: May 17, 2018.

[12] A.R. Martinez, Swirling seas of plastic trash, June 22, 2011, https://www.sciencenewsforstudents.org/ article/swirling-seas-plastic-trash, Accessed: May 17, 2018.

[13] S. Medvedeva, V. Anisimov, Water, Intention Media Inc., 2008.

[14] United Nations, International Decade for Action "WATER FOR LIFE" 20052015,

http://www.un.org/waterforlifedecade/hu man_right to_water.shtml, Accessed: May 18, 2018.

[15] A. Widom, Y. Srivastava, V. Valenzi, The Biophysical Basis of Benveniste Experiments: Entropy, Structure, and Information in Water, International Journal of Quantum Chemistry 110(2010), 252-256.
[16] J. Dunning-Davies, Structure and Memory in Water, Research Gate, January 2011, https://www.researchgate.net/profile/J_D unning-

Davies/publication/228611683_Structure and_Memory_in_Water/links/Odeec519 1339f2b93a000000/Structure-andMemory-in-Water.pdf, Accessed: May 18, 2018.

[17] L. Montagnier, E. Del Giudice, J. Aïssa, C. Lavallee, S. Motschwiller, A. Capolupo, R.A. Polcari, P. Romano, A. Tedeschi, G. Vitiello, Transduction of DNA information through water and electromagnetic waves, Electromagnetic Biology and Medicine 34(2015) 2, 106112.

\section{Acknowledgements}

This paper describes the results of the research carried out within the Project "Centar održivog razvoja" / "Center for Sustainable Development", co-financed by the European Regional Development Fund and implemented within the Operational Programme Competitiveness and Cohesion 2014 - 2020, based on the call "Investing in Organizational Reform and Infrastructure in the Research, Development and Innovation Sector". 